\title{
NON-AGENDA
}

With the view of causing an increase to take place in the mass of national wealth, or with a view to increase of the means either of subsistence or enjoyment, without some special reason, the general rule is, that nothing ought to be done or attempted by government. The motto, or watchword of government, on these occasions, ought to be - Be quiet...Whatever measures, therefore, cannot be justified as exceptions to that rule, may be considered as non-agenda on the part of government.

— Jeremy Bentham (c.1801)

\section{News and Social Policy: Reporting of Suicide and Mental Illness}

\section{R. Warwick Blood, Jane Pirkis and Catherine Francis}

$\mathrm{T}$

This paper elaborates how contemporary communication and media theory can contribute toward the continuing development of national mental health and suicide prevention strategies and related public policy. The initial focus is on critical reviews of the existing international research literature and the underlying framework and methods used in an extensive monitoring study of Australian media reporting practices, which was funded by the then Commonwealth Department of Health and Aged Care. We then describe how our research program has moved to investigations of the nature of medical and health professional, journalistic and lay discourses, including of those diagnosed with mental illness, about suicide and mental health. This research, necessarily independent of government, draws on risk and cultural theory.

Suicide and mental illness are significant health problems in Australia. In 2002, there were 2,320 suicides or a crude rate of 11.8 per 100,000 people. The rate for males was much higher than for females and there was considerable variability across age groups. For males, the highest age-specific suicide death rate was 31.1 per 100,000 , recorded for those in the 25-29 year age group. For females, the highest rate was 9.7 per 100,000, recorded for those in the 40-44 year age group (Australian Bureau of Statistics, 2003).

Mental illness affects one in five Australians (Andrews et al., 1999), with this figure including common and often debilitating disorders such as depression, anxiety and substance abuse, as well as conditions like schizophrenia. Not only is

R. Warwick Blood is Professor, School of Professional Communication, University of Canberra, Jane Pirkis is Associate Professor, and Catherine Francis, Research Fellow, School of Population Health, University of Melbourne. 
the prevalence of mental illness high, so too is the burden of disease due to mental disorders. Depression alone is recognised as the most important single cause of non-fatal disability (Mathers et al., 1999).

\section{The Werther Effect and Short-Term Media Effects}

During the past decade, several countries have introduced resource kits or guidelines for editors and journalists to mediate news reporting and portrayal of suicide, and mental health and illness, issues. These resources can be viewed as public health interventions and are a direct response to what many medical and health professionals see as irresponsible journalistic practices. Australia's original media resource kit, Achieving the Balance (Commonwealth Department of Aged Care, 1999) was revised and re-issued in August 2002 as Reporting Suicide and Mental Illness: a Resource for Media Professionals (Commonwealth of Australia, 2002). Both resource kits were developed in cooperation with editors, journalists, health and medical professionals and consumers. Overseas research by Michel and his colleagues (2000) demonstrated that such resources can have a positive impact on the behaviour of journalists and editors and, similarly, studies by Etzerdorfer and colleagues (1992; 1998) suggest that this changed behaviour can translate into a positive impact on suicide rates.

Nonetheless, the international research program that underpins these interventions can be questioned for its narrow focus and simplistic position, which primarily questions whether media exposure leads to imitation, or copycat suicides - a direct, short-term media effect. Or, in the case of mental health, does negative media coverage lead to or reinforce community stigma about mental illness? The media-suicide link has been debated for centuries but it is only in recent times that systematic research has been conducted. In the often-quoted classic, The Sorrows of Young Werther (Goethe, 1774), the hero shot himself because his love was unattainable. Subsequently, a reported increase in suicide rates in European countries led to the proposition that some readers were imitating Goethe's hero and the book was banned. Phillips (1974) in his research program introduced the term the 'Werther Effect' to describe the proposed causal relationship between media portrayals of suicide and imitation acts, including completed suicides, attempted suicides and suicidal ideation.

To establish causality we critically examined all available studies to determine whether they demonstrated the existence of a relationship between media portrayal of suicide and actual suicidal behaviour. Once we determined that the majority did point to a relationship, we used Hill's (1971) criteria (that is, consistency, strength, temporality, specificity and coherence) to judge whether the association was causal. Our critical review of the international research literature (Pirkis and Blood, 2001a; 2001b; 2001c) for the Commonwealth Department of Health and Aged Care concluded there is a causal association between nonfictional media portrayals of suicide and actual suicide in some cases (the evidence is more equivocal in the case of fictional presentations of suicide in television or in films and music). The effect is strongest immediately after the 
media presentation (attenuating over time), when the portrayals are prominent, when the imitator reveres the model as a celebrity or identifies with them as a peer, and when the method is explicitly described. In addition, the effect cannot be explained as a 'bringing forward' of suicide deaths that would have occurred anyway, since the increase in suicide rates observed after media portrayals is not later followed by a commensurate drop in rates. Other international reviews have reached similar conclusions to our own (see, for example, Schmidtke and Schaller, 1998; Martin, 1998).

Research examining relationships between reporting and mental health/illness is broader in scope but is still largely focused on the potential for direct media effects. Our review (Francis et al., 2001) of media and mental health coverage, which was also commissioned by the Commonwealth Department of Health and Aged Care, found an overwhelming tendency by the media to portray mental illness in a negative manner, especially in linking mental illness to violent acts. The review suggested that these portrayals lead to negative community attitudes and beliefs about mentally ill people. (Also see, Francis et al., 2003; Blood, Putnis and Pirkis, 2002).

Only one refereed study has been published in Australia examining the Werther Effect. Hassan (1995) identified what he categorised as 'high impact' suicide stories published in the Australian press - The Age (Melbourne) and The Sydney Morning Herald - between 1981 and 1990 and found that the national daily average suicide rate for males (but not females) increased significantly after such stories. Hassan argued (1995:482) that the gender difference might reflect the newspapers' emphasis on reporting male suicides thus increasing possible imitation. Males are also heavier newspaper readers than females. The gender difference may also be related to the lethality of suicide method used by males; males tend to use more violent, lethal methods than females.

Research investigating the Werther Effect and the impact of media coverage on community stigma of mentally ill persons does have a significant impact on public policy internationally and, to some extent, on journalistic practices and standards. The Australian resource kit points repeatedly to these reviews of the international literature. But we recognise the lack of systematic Australian research on the Werther Effect and are currently investigating the relationship between Australian media reporting of suicide and suicidal behaviour, using data from the Australian Bureau of Statistics, the Australian Institute of Health and Welfare, and the Victorian Department of Human Services. ${ }^{1}$

The critical literature reviews also pointed to weaknesses in research designs, gaps in knowledge, and provided a critique of the overall direction of the international Werther Effect research program (Blood and Pirkis, 2001). Prior to our media monitoring project, relatively little was known about the extent or nature of media portrayals of suicide in traditional print and broadcast media, or

1 This research, 'The Impact of Media Reporting of Suicide on Actual Suicidal Behaviour' is funded by the Australian Rotary Health Research Fund. (Principal Investigator, Jane Pirkis). 
variations in coverage across media genres. Little is still known about the impact of multimedia and the Internet. The ways various audiences might use the mediated information about suicide and mental health issues is also unexplored. Other gaps in knowledge include explication of the social learning model used to support imitation effects, especially the relationship between model and observer. We know little about whether at-risk individuals actively seek reports of others' suicides in order to validate their own experiences or to assist in the steps towards completion of suicide. Importantly, the extent to which responsible reporting of suicide may have a positive impact on suicidal behaviours has not yet been systematically investigated.

The conclusions from the critical reviews informed the creation of a revised media resource kit for Australian editors and journalists but were only a first step. How do the Australian media perform in reporting suicide and mental health and illness? In completing this task, the literature reviews set critical parameters for the completion of the first media monitoring study of its kind in Australia.

\section{A Double Switch of Emphases — The Australian Media Monitoring Project}

The Media Monitoring Project, one of the largest of its kind internationally, was designed to provide practical advice for developing communication strategies for the Commonwealth Department of Health and Aged Care, including informing the revision of the media resource kit. The project also aimed to suggest future ways of monitoring media coverage of suicide, mental illness, and mental health news and information.

Critically, the project involved a double switch of emphases. First, there was a deliberate move away from investigations of only short-term, direct effects of the news media toward examinations of the longer-term 'picture' of suicide and mental health information that is available to media audiences. Specifically, using both quantitative and qualitative methods, we examined the extent and nature of media reporting and portrayals. Secondly, as our research progressed, we moved away from examinations of the content of specific media types (newspapers or television or radio) toward specific considerations of media genres (for example, news radio versus talkback radio or television news versus television current affairs).

The Commonwealth decided that both quantitative and qualitative approaches to assessing media content could make significant contributions to the project's objectives and determined that, together, our two research teams (from the University of Melbourne and the University of Canberra) could provide both. This decision to fund a cooperative effort between two groups of researchers who did not know each other was a bold decision but it had an important theoretical impact on the overall research direction. The University of Melbourne's expertise in health program evaluation, mental health epidemiology and policy issues was coupled with Canberra's expertise in qualitative media analysis and media policy 
issues - all under the guiding umbrella of a double switch in emphases; a contrast to what had been previously researched internationally.

The task of monitoring one year of Australian media content comprised two components. A content analysis of all major metropolitan Australian newspapers, all newspapers published in the state of Victoria, and randomly selected capitalcity broadcast news and current affairs programs was conducted between March 2000 and March 2001 (Pirkis et al., 2001). Critically, this research assessed the quality of media performance by rating individual news items against a ninedimension scale that was based on criteria in the resource kit distributed to editors and journalists. The nine dimensions were:

(1) Does the item have any examples of inappropriate language?;

(2) Is the item inappropriately located?;

(3) Is the word 'suicide' used in the headline?;

(4) Is a photograph/diagram or footage depicting the suicide scene, precise location or method used with the item?;

(5) Is there a detailed discussion of the method used?;

(6) Is the person who died by suicide a celebrity?;

(7) Is suicide portrayed as 'merely a social phenomenon' as opposed to 'being related to mental disorder'?;

(8) Does the item provide information on help services?; and

(9) Are the bereaved interviewed?

A similar procedure, using the guidelines, was adopted for the construction of an index for mental illness quality or compliance.

A total quality or compliance measure, combining the separate suicide and mental illness ratings, which added to our knowledge of the extent and nature of suicide and mental illness coverage, was then computed for newspapers, television and radio. The resulting analysis enabled inter-media and overall summary indices of guideline compliance to be computed and compared against such variables as story type, story topic and, gender and age of the principal actor in the story.

Secondly, qualitative textual analyses of selected newspaper and broadcast media stories and features drawn from the quantitative study were completed. This research investigated how Australian media routinely and characteristically framed suicide and mental health and illness, and how news reports were treated in differing genres - for example, between 'straight news' compared to column or opinion pieces, or between talkback radio coverage and radio news. Research also identified the principal actors - politicians, policy makers, health and medical experts, journalists, editors, or lay-people — who were setting the agenda of news and information about suicide, and mental health and illness issues.

News frame analysis, the guiding theoretical approach in the qualitative analyses (Reese, Gandy and Grant, 2000; Entman, 1993; Gamson and Modigliani, 1989) investigates how news texts are presented and made understandable to audiences. In constructing 'the news', editors and journalists are constrained by 
their daily routine practices, their conception of what makes 'news', the imperatives of their media organization, and social and cultural influences, including their understandings and perceptions of audiences. The story's frame, which is normally signalled in the headline or broadcast news lead, directs the reader to attend to what is in the frame and not to what is excluded. Framing sets limits on the information available to audiences who are trying to make sense out of the reported event, which is usually beyond their direct, personal experience. Gamson (1992) argued that a journalist's sense of news values leads them to present issues within certain frames, often reflecting broader cultural themes and narratives that help define ideas available to audiences as they talk and think about the issue.

Additionally, this phase of the research examined various case studies - the suicide death of Greg Wilton, MP; language routinely used in news discourse about mental health, especially the word, schizophrenia; reporting of suicide and mental illness statistics and trends; media portrayals in popular magazines; and parliamentary discourse about suicide (Blood et al., 2002).

The combined quantitative and qualitative approach allowed for the systematic investigation of the range of meanings about suicide and mental health available to audiences in Australian media content. This identification of the longer-term 'picture' was informed by recent developments in media audience and reception theory (Alasuutari, 1999; Tulloch and Lupton, 1997).

A full account of the quantitative content analyses and quality analyses, and the news frames and framing devices identified by the qualitative research, can be found in Francis et al. (2004), Pirkis et al. (2002), Blood, Putnis and Pirkis (2002), Pirkis et al. (2001) and Blood et al. (2001).

In summary, the quantitative investigations found that the nature of suicide reporting was extensive and highly variable. Suicide news tended to be about completed suicide rather than attempted suicide or suicidal ideation. These stories most commonly involved individuals, policy or program initiatives or statistical overviews of suicides in the population. Mental illness items tended to be about policy or program initiatives, causes, symptoms or treatment of mental illness, mental health care or services, research, or an individual's experiences. Males and young people commonly featured in suicide stories, as did people living in rural areas. Psychiatric patients, people in custody and Aboriginal and Torres Strait Islander people also featured prominently. Young people were consistently given prominence in mental health and illness news.

The quantitative index of quality (or compliance with the suggested guidelines) showed that suicide items had lower scores than did mental health and illness items. Several factors associated with item content were predictive of quality. The poorest quality suicide items were those that described murdersuicides or mass suicides, or provided a statistical overview of completed suicide, or presented legal issues associated with suicide. The poorest quality mental health and illness items were those that described an individual's experience of mental illness, reported on mental health services or care, or used mental health language inappropriately or out of context (such as 'schizophrenic city'). The 
suicide death of Greg Wilton, MP was the most prominent story during the study's time frame (Putnis, Blood and Payne, 2002).

In summary, the qualitative analyses demonstrated that many suicide stories resulted from information collected by journalists at courts, coroner's courts or from the police. These items were the most problematic in terms of compliance with the suggested guidelines for reporting. Common concerns were the use of the word suicide in headlines and broadcast leads, prominence given to the story, video and photographs of the scene, and details of the method of suicide. Often crime and court stories involved news frames of fear, horror and shock. Sensational or inappropriate language in the headlines and broadcast leads in these types of stories were common. Framing devices identified in other types of suicide stories included those involving public interest, national social or political interest, oddity or the unusual, prominence of the person, or celebrity devices. Suicide stories that did not fit these dominant frames were rarely reported. Many suicide stories did not contain contact details for audiences about where to access mental health help or services. Against this trend were many stories that that focused on suicide risk factors and suicide prevention. This was especially the case for regional and rural newspapers and radio.

The most problematic coverage of mental health and illness news was sourced to the courts, coroner's courts or the police. Many of these stories focused on violence and many included graphic images of violence. While these stories related to specific individual experiences that are relatively rare, audiences are likely to draw generalised inferences about mentally ill people from this coverage. The ways in which audiences label or categorise individuals or groups is determined in part by the way the events are framed by the media. News stories about extreme or rare cases, such as linking mental illness to violence, tend to stigmatise mental illness and generate fear of mentally ill people in the community. Inappropriate language and language used out of context were identified concerns as was the tendency of some media genres to portray mental illness as bizarre or an oddity. Many stories and features across all genres reflected community concern about mental health, and frames were centred on government funding issues, mental health policy, new research or treatment, statistical overviews, and the city versus the bush conflict.

The monitoring project provided the first comprehensive and systematic baseline picture of Australian media reporting and portrayal of suicide and mental illness news, and informed the revision of the Reporting Suicide and Mental Illness (Commonwealth of Australia, 2002). The findings were also of value to the Response Ability project - a short-course training package developed by the Hunter Institute of Mental Health for use by Australian undergraduate university journalism courses (Hunter Institute of Mental Health, 2001).

The project, however, was not designed to investigate how audiences, especially those who might be said to be at-risk, might interpret and manage information about suicide and mental illness news in their everyday lives. Limited to analyses of media content, the project left unanswered many questions about potential audience reception. Equally critical questions arising from the clash 
between journalistic imperatives and those of the government, or medical and health professionals, were not really assessed.

\section{A Clash of Professional Imperatives}

Throughout the media monitoring project for the Commonwealth Department of Health and Aged Care, we met regularly with a Media Reference Group, which comprised medical and health professionals, consumers, and media industry representatives. Media groups included the Australian Internet Industry Association, the then Federation of Australian Radio Broadcasters and Federation of Australian Commercial Television Stations, the Australian Press Council and advertising industry groups. These discussions provided the opportunity for open dialogue between the Commonwealth Department of Health and Aged Care, consumers, the media, with our input of emerging findings from the on-going research. Participants, to a greater or lesser extent, viewed this process as an opportunity to discuss frankly their concerns and assessments of our research, other research, and various proposed communication strategies.

Clearly, the Commonwealth Department of Health and Aged Care recognised that media resources or guidelines needed to be produced in active conversation with relevant stakeholders, including editors and journalists, and media industry associations. This did not mean, of course, that there was agreement on all issues all of the time or that there will agreement on issues in the future. Indeed, the contrary was often the case.

For example, the quantitative monitoring study and the complementary qualitative textual analyses were based primarily on the original guidelines, Achieving the Balance (Commonwealth Department of Health and Aged Care, 1999). Our measure of quality (or compliance) was directly linked to the guidelines. But it is clear that these guidelines are contested by many editors and journalists. Some journalists see them as an intrusion on their professional practice, others talk of 'political correctness', while many have never seen them.

Evidence of the clash over meaning can be seen in the Australian Press Council's response to research on the Werther Effect. The Council (2000:6) dismisses the Hassan (1995) evidence of a news-suicide link (detailed above) as 'tenuous at best' and questions whether there is a causal relationship between newspaper reports and actual suicide in Australia and, significantly, overseas. While promoting responsible and sensitive coverage, the Council has argued that resource kits or guidelines should not be prescriptive or start from a presumption of harmful effects.

Our monitoring research also pointed to this contest with the identification of a few news items that did not comply with the guidelines but appeared to have other positive features. For example, a news feature in The Sydney Morning Herald (16 September 2000) on the inquest in Darwin into the death by suicide of a young Aboriginal boy was analysed to show how a story can depart for seemingly valid reasons from the suggested guidelines. In this case, it appeared that the journalist's intention was to describe in shocking and graphic detail the 
method of suicide - gross departure from the guidelines. Yet the clear purpose of the feature was to draw attention to the seriousness and national issues involved. Vulnerable groups, of course, could interpret the story in different ways. But can we reasonably expect editors and journalists to take account of all possible audiences and audience readings?

\section{Competing and Contested Discourses}

Our on-going research ${ }^{2}$ views the contestation of knowledge about suicide and mental illness news as a cultural activity involving a struggle over different discursive constructions of mental health and illness - in the media by editors and journalists, by medical and health professionals, and by audiences dealing with these issues in everyday experience (Phillips, 2000; 1999). Such a program is independent of government, medical/health professionals and the journalism industry but we recognise that we too hold a position, which demands considerable reflexivity on our part.

For example, to report in a news story about a 'schizophrenic killer' or 'a wanted psych ward escapee' may have profound influence on the way the issue is perceived and acted upon by policy makers, government and various audiences. Journalistic decisions about what constitutes news, the emphasis given to some 'facts' to the exclusion of others, and the language and style of the story, stem from daily routine practices and the journalist's understanding and perceptions of their intended audience. But anecdotal evidence suggests that such media labels or frames may have a profound negative influence on at-risk groups.

Some news media genres, for example, routinely link mental illness to violence and frame their stories around 'public risk' using alarmist imagery - a tendency all too evident in the genre of court reporting (Francis et al., 2003; Blood, Putnis and Pirkis, 2002). Yet Australian evidence (Wallace, Mullen and Burgess, 2004) shows that the links between mental illness and violent crime (and comorbid substance use disorders) is simply not explained by single factors; it is very complex. The Wallace study found that schizophrenia was associated with a higher rate of criminal convictions but the rate of convictions over the 25 year study period was similar among schizophrenic patients and comparison subjects, despite a change from predominantly institutional to community care, and a dramatic escalation in the frequency of substance abuse problems among persons with schizophrenia.

Similarly, UK empirical evidence shows that mental illness is not commonly an associated factor in homicides. Perpetrators of stranger homicides are less likely to have a mental illness, or to have been under mental health care, than perpetrators of homicides in general (Shaw et al., 2004). This research received

2 This research, 'Communicating Risk: Journalistic News Values, and Medical, Health Professional and Lay Discourses on Suicide and Mental Illness' is funded by the Australian Research Council (Chief Investigators, Warwick Blood, Jane Pirkis, Graham Martin). 
coverage in specialist $\mathrm{ABC}$ programming but not in the mainstream press or broadcast media.

But our qualitative, interpretive news frames are our readings of the news texts; they are static researcher designations. We do not know how various audiences, particularly people diagnosed with mental illness or people who might be said to be at risk of self harm, read and understand this information - or whether they misinterpret it, resist it, or ignore it all together.

Thus, our research program begins by recognizing this contest over risk knowledge. We position the interactions between various stakeholders as a process of risk communication where each stakeholder attempts to persuade others of the validity of their assessments and interpretations. In our context, for example, risk assessments relate to the efficacy of media reporting resources or guidelines, or the potential impact of media portrayals on people diagnosed with mental illness, or public perceptions of mental illness and mentally ill people, etc. We recognise that our technical, 'expert' knowledge will always be perceived by other stakeholders as uncertain or tenuous, or perhaps even ambiguous, or as Wynne (1992:276) puts it, as conditional knowledge.

The research involves analyses of the discourses of editors and journalists, medical and health professionals, and people diagnosed with mental illness. It explores the extent of social and personal reflexivity about suicide and mental health/illness against a background of contested information and sources of information. In this context, reflexivity means responses to active, changing conditions that arouse anxiety and fear; responses that involve a continual monitoring by people — a 'weighing up' of assessments and claim-makers, especially of those who claim to be experts (Lupton, 1999a; Giddens, 1990).

Risk theory also alerts us to recognise that risks are socially defined and acted upon (Tulloch and Lupton, 2003; Lupton and Tulloch, 2002; Lupton, 1999a, 1999b). Wynne (1996) argues that exploring lay discourse, as well as 'expert' discourses, is critical to understanding risk (also see, Wynne 1992). Most discourse about risk - say, the impact of suicide news stories — take place at the technical or governmental level but these issues are dealt with by most people as individuals in very specific situations - at the local level in private, everyday experience by lay people, for example, or by journalists and editors facing a myriad of professional and workplace constraints.

Recent research and theorizing on news framing processes (Reese, Gandy and Grant, 2001) outlines a complementary perspective. Miller and Riechert (2001:109) define a news frame as:

an on-going process by which ideological interpretive mechanisms are derived from competing stakeholder positions. These selectively representative frames are manifest in the choice and range of terms that provide the context in which issues are interpreted and discussed.

As a consequence, we continue both quantitative and qualitative analyses of media content about suicide and mental health and illness news in addition to 
talking to key stakeholders. We note that the dynamic, often-changing, interplay between events and media coverage led Kitzinger and Reilly (1997:346) to argue that while it is important to investigate news practices and routines it is also critical to identify instances where "there is alleged to be a "collapse of journalistic standards" or a "dereliction of journalistic duty". If editors and journalists frame news in specific and characteristic ways, this inevitably leads to questions about the consequences of those framing decisions.

For example, Reese (2001:13) identified power relations among stakeholders as critical in elaborating the ideological structure of news and he labelled some news frames as strategic frames, which organise not just one story but provide audiences with an enduring cultural understanding beyond the immediate daily news. Is mental illness news framed as violence an enduring news frame in the Australian press? Similarly, Kitzinger (2000:75) coined the term 'media template' - a news frame that is so dominant it becomes the key reference point in news discourse and is transposed from one event to other events. Media templates routinely highlight one perspective and serve as a kind of rhetorical shorthand helping both journalists and their audiences to make sense of new stories and perspectives. Has the frequently used 'paranoid schizophrenic killer' become a media template?

In summary, the key outcomes for government and other stakeholders centre on a different way of examining the claims and counter-claims about media coverage of suicide and mental health/illness and its potential impact. Following Lupton (1999b), what is the nature and extent of individual and social reflexivity about suicide and mental health/illness? How do people categorised as being 'at risk' respond to the imperatives of expert knowledge and government? What role do the media play in constructing risk knowledge? What types of information do stakeholders trust and use in developing their logics of risk in this context?

\section{Concluding Remarks}

From a health policy perspective, the current research, which builds on our previous work and that of others, re-frames the national and international debate by gaining a better understanding of key stakeholder views and positions. It identifies and investigates the many questions that arise from the clash between the imperatives of news organizations and the imperatives of government and medical/health professional interventions designed to improve news reporting and portrayal. The National Mental Health Strategy and the National Suicide Prevention Strategy are implemented within the context of various discourses medical, health professional, governmental, journalistic, editorial, and lay discourses. It is the dynamics of communicative interactions and contexts that are significant. Understanding these changing and often competing discourses can create frameworks for future sustainable communication strategies. Such strategies are of vital health importance to the nation and are watched closely by overseas governments and researchers. These observations will be important for 
the international research community working in suicide and mental health/illness media research in further extending the boundaries of the current debate.

\section{References}

Alasuutari, P. (1999), Rethinking The Media Audience, Sage, Thousand Oaks, Calif.

Andrews, G., W. Hall, M. Teesson and S. Henderson (1999), The Mental Health of Australians, Commonwealth Department of Health and Aged Care, Canberra.

Australian Bureau of Statistics (2002), Suicides: Recent Trends, Australia, Australian Government, Canberra.

Australian Press Council (2000), Australian Press Council News 12(3), August, Sydney.

Blood, R.W., Putnis, P. and Pirkis, J. (2002), 'Mental Illness as Violence: A News Frame Analysis of the Reporting and Portrayal of Mental Health and Illness in Australian Media, Australian Journal of Communication 29(2):59-82.

Blood, R. , P. Putnis, T. Payne, J. Pirkis, C. Francis, K. McCallum, and D. Andrew (2002), How the Australian Media Report and Portray Suicide, and Mental Health and Illness: The Case Studies, Commonwealth Department of Health and Aged Care, Canberra.

Blood, R. and J. Pirkis, (2001), 'Suicide and the Media: (3) Theoretical issues', Crisis 24(3):163-169.

Blood, R., P. Putnis, J. Pirkis, C. Francis and Payne T. (2001), A Qualitative Analysis of the Reporting and Portrayal of Suicide, and Mental Health and Illness, in the Australian Media, Commonwealth Department of Health and Aged Care, Canberra.

Commonwealth of Australia (2002), Reporting Suicide and Mental Illness: A Resource for Media Professionals, Canberra.

Commonwealth Department of Health and Aged Care (1999), Achieving the Balance: A Resource Kit for Australian Media Professionals for the Reporting and Portrayal of Suicide and Mental Illnesses, Commonwealth of Australia, Canberra.

Entman, R. (1993), 'Framing: Towards Clarification of a Fractured Paradigm,' Journal of Communication 43(4):51-58.

Etzerdorfer, E. and G. Sonneck, (1998), 'Preventing Suicide by Influencing Mass-Media Reporting. The Viennese Experience 1980-1996', Archives of Suicide Research 4 (1):6774.

Etzersdorfer, E., G. Sonneck, and S. Nagel-Kuess, (1992), 'Newspaper Reports and Suicide', [Letter], New England Journal of Medicine 327 (7):502-3.

Francis, C., J. Pirkis, R. Blood, D. Dunt, P. Burgess, B. Morley, A. Stewart, and P. Putnis (2004), 'The Portrayal of Mental Health and Illness in Australian Non-Fiction Media', Australian and New Zealand Journal of Psychiatry 38:541-546. 
Francis, C., J. Pirkis, R. Blood, P. Burgess, and D. Dunt, (2003), 'Media Reporting of Specific Mental Illnesses in the Context of Crime: Implications for Mental Health Literacy’ [Letter], Medical Journal of Australia 176(1/15 December):638.

Francis, C., J. Pirkis, P. Burgess, D. Dunt, and R. Blood, (2001), Mental Health and Illness in the Media: A Review of the Literature. Commonwealth Department of Health and Aged Care, Canberra.

Gamson, W. (1992), Talking Politics, Cambridge University Press, New York.

Gamson, W. and A. Modigliani (1989) 'Media Discourse and Public Opinion on Nuclear Power: A Constructionist Approach,’ American Journal of Sociology 95 (1):1-37.

Giddens, A. (1990), The Consequences of Modernity, Polity Press, Cambridge.

Goethe, W. von (1774), The Sorrows of Young Werther [trans. M. Hulse (1989)], Penguin Classics, London.

Hassan, R. (1995), 'Effects of Newspaper Stories on the Incidence of Suicide in Australia: A Research Note', Australian and New Zealand Journal of Psychiatry, 29(3):480-3.

Hill, A. (1971), Principles of Medical Statistics, Lancet, London.

Hunter Institute of Mental Health (2001), Response Ability: Resources for Journalism Education, Newcastle.

Kitzinger, J. (2000), 'Media Templates: Patterns of Association and the (re)Construction of Meaning Over Time', Media, Culture and Society 22:61-84.

Kitzinger, J. and J. Reilly (1997), 'The Rise and Fall of Risk Reporting: Media Coverage of Human Genetics Research, 'False Memory Syndrome' and Mad Cow Disease', European Journal of Communication 12 (3):319-350.

Lupton, D. (1999a), Risk, Routledge, London.

Lupton, D. (1999b), Risk and Sociocultural Theory: New Directions and Perspectives,. Cambridge University Press, Cambridge.

Lupton, D and J. Tulloch (2002), “ "Risk is Part of Your Life”: Risk Epistemologies Among a Group of Australians’, Sociology 36 (2):317-334.

Martin, G. (1998), 'Media Influence to Suicide: The Search for Solutions', Archives of Suicide Research 4:51-66.

Mathers, C., E. Vos, C. Stevenson and S. Begg (2001), 'The Burden of Disease and Injury in Australia', Bulletin of the World Health Organization 79 (11):1076-1084.

Michel, K., C.Frey, K. Wyss and L. Valach (2000), 'An Exercise in Improving Suicide Reporting in Print Media', Crisis 21 (2):71-80.

Miller, M. and B. Riechert, (2001), 'The Spiral of Opportunity and Frame Resonance: Mapping the Issue Cycle in News and Public Discourse', pp. 107-121 in S. Reese, O. 
Gandy and A. Grant (eds), Framing Public Life: Perspectives on Media and Our Understanding of the Social World, Lawrence Erlbaum Associates, Hillsdale, NJ.

Phillips, L. (2000), 'Mediated Communication and the Privatization of Public Problems: Discourse on Ecological Risks and Political Action', European Journal of Communication 15 (2):171-207.

Phillips, L. (1999), 'Risk, Reflexivity and Democracy’, Nordicom Review 2:115-136

Phillips, D. P. (1974), The Influence of Suggestion on Suicide: Substantive and Theoretical Implications of the Werther Effect', American Sociological Review 39(3):340354.

Pirkis, J., C. Francis, R. Blood, P. Burgess, B. Morley, A. Stewart and P. Putnis (2002), 'Reporting of Suicide in the Australian Media', Australian and New Zealand Journal of Psychiatry 36(2):190-197.

Pirkis, J. and R. Blood (2001a), Suicide and the Media: A Critical Review, Commonwealth Department of Health and Aged Care, Canberra.

Pirkis, J. and R. Blood (2001b), 'Suicide and the Media: (1) Reportage in Non-Fiction Media', Crisis 22(4):146-154.

Pirkis, J. and R. Blood (2001c), 'Suicide and the Media: (2) Portrayal in the Fiction Media', Crisis 22(4):155-162.

Pirkis, J., C. Francis, R. Blood, P. Burgess, B. Morley, A. Stewart and P. Putnis (2001), A Quantitative Analysis of the Reporting and Portrayal of Suicide, and Mental Health and Illness, in the Australian Media, Commonwealth Department of Health and Aged Care, Canberra.

Putnis, P., R. Blood, and T. Payne (2002), 'Death of a Politician: Australian Media Reporting and Portrayal of the Death of Greg Wilton, MP', Australian Journalism Review 24(2):21-40.

Reese, S. (2001), 'Prologue — Framing Public Life: A Bridging Model for Media Research', pp. 7-31 in S. Reese, O. Gandy and A. Grant (eds), Framing Public Life: Perspectives on Media and Our Understanding of the Social World, Lawrence Erlbaum Associates, Hillsdale, NJ.

Schmidtke, A. and Schaller, S. (1998), 'What do we Know About Media Effects on Imitation of Suicidal Behaviour: State of the Art', pp. 121-137 in D. de Leo, A. Schmidtke and R. Diekstra, Suicide Prevention: A Holistic Approach, Klewer Academic Publishers, Dordrecht.

Shaw, J. T. Amos, I. Hunt, S. Flynn, P. Turnbull, N. Kapur and L. Appleby (2004), 'Mental Illness in People Who Kill Strangers: Longitudinal Study and National Clinical Survey’, British Medical Journal 328:734-737.

Tulloch, J. and D. Lupton (2003), Risk and Everyday Life, Sage, London.

Tulloch, J. and D. Lupton (1997), Television AIDS and Risk: A Cultural Studies Approach to Health Communication, Allen \& Unwin, Sydney. 
Wallace, C., P. Mullen, and P. Burgess (2004), 'Criminal Offending in Schizophrenia Over a 25 Year Period Marked by Deinstitutionalization and Increasing Prevalence of Comorbid Substance Use Disorders', American Journal of Psychiatry 161 (4):716-37.

Wynne, B. (1992), Risk and Social Learning: Reification to Engagement', pp. 275-297 in S. Krimsky and D Golding (eds.), Social Theories of Risk, Praeger, London.

Wynne, B. (1996), 'May the Sheep Safely Graze? A Reflexive View of the Expert-Lay Knowledge Divide', pp. 44-83 in B Lash, B. Szerzynski and B Wynne, B (eds), Risk, Environment and Modernity, Sage, London.

We acknowledge the contributions from our project teams: Associate Professor David Dunt, Belinda Morley and Andrew Stewart at the University of Melbourne (along with Professor Philip Burgess, then from the Mental Health Research Institute), and Professor Peter Putnis, Dr Trish Payne, Kerry McCallum, Jordan Williams and Kate Holland at the University of Canberra. We also acknowledge the assistance of Professor Graham Martin, the University of Queensland. We also thank two anonymous referees for their comments.

The views in this paper are those of the authors and do not necessarily represent the views of the Commonwealth of Australia. The then Mental Health and Special Programs Branch, Commonwealth Department of Health and Aged Care, funded the Media Monitoring Project and we acknowledge the contributions by members of the Media Reference Group. 